\title{
Analisis Enterprise Risk Management Menggunakan FMEA pada PT XYZ
}

\author{
Mu'adzah*1), Nunung Agus Firmansyah ${ }^{2)}$ \\ Teknik Industri, Fakultas Sains Teknologi dan Matematika, Universitas Muhammadiyah Kudus \\ Jln. Ganesha I Purwosari, Kudus, 59316, Indonesia \\ E-Mail:muadzah@umkudus.ac.id ${ }^{l)}$,nunungagus@umkudus.ac.id ${ }^{2}$
}

\begin{abstract}
ABSTRAK
PT. XYZ adalah perusahaan pembuat kertas di Kabupaten Kudus, perusahaan ini memproduksi produk kemasan. Apabila terdapat kemungkinan kegagalan atau risiko pada setiap departemen dalam perusahaan, maka perusahaan perlu melakukan manajemen risiko untuk mengarahkan dan mengendalikan aktivitas perusahaan yang berisiko, sebagai jaminan atas tujuan strategis perusahaan. Pada penelitian ini dilakukan pemeriksaan resiko pada Departemen K3 dan Lingkungan, PPIC, Pengendalian Mutu, Produksi, Pengadaan dan Pergudangan, serta departemen Teknik terkait dengan kegiatan produksi yang ada pada Divisi Papermill di PT XYZ. Penelitian ini menggunakan metode Failure Mode and Effect Analysis (FMEA). Dilihat dari risiko yang perlu segera diselesaikan dengan melihat nilai RPN, kemudian di breakdown pada matriks prioritas risiko, terdapat 10 risiko tinggi, 13 risiko sedang dan 8 risiko rendah.
\end{abstract}

Kata kunci: Enterprise Risk Management, FMEA, Risk Assessment

\section{Enterprise Risk Management Analysis using FMEA at PT XYZ}

\section{ABSTRACT}

PT. XYZ is a paper manufacturing company in Kudus Regency, this company produces packaging products. If there is a possibility of failure or risk in every department in the company, the company needs to carry out risk management to direct and control risky corporate activities, as a guarantee of the company's strategic objectives. In research that carries out risk checks on the Department of K3 and Environment, PPIC, Quality Control, Production, Procurement and Warehousing, and Engineering department related to production activities in the Papermill Division at PT XYZ. This research uses the Failure Mode and Effect Analysis (FMEA) method. Judging from the risks that need to be resolved immediately by looking at the RPN value, then breakdown in the risk priority matrix, there are 10 high risks, 13 medium risks and 8 low risks.

Keywords: Enterprise Risk Management, FMEA, Risk Assessment

\section{Pendahuluan}

PT XYZ merupakan perusahaan pribadi yang dibangun pada tahun 1900an sebagai percetakan di Kudus. Pengembangan sumber daya manusia yang intensif dengan cara membangun sebuah karakter (prioritas yang diikuti pula dengan pelatihan teknis dan mampu untuk memanage sesuatu akan dapat membuat sebuah budaya) yang dapat berinovasi dan membentuk suatu kemajuan perusahaan. Hal ini yang menjadi budaya di PT.XYZ, sebuah budaya yang menjadi filosopi perusahaan. Setelah tiga dekade, PT XYZ telah berkembang menjadi group teritegrasi dari divisi manufaktur, percetakan, pengepakan, produksi kertas, konverta, permesinan, anti counferting, katu elektronik dan label teknologi tinggi. PT XYZ sekarang diantara yang terbesar di dunia industri percetakan dan pengepakan di Asia Tenggara.

PT XYZ meskipun menjadi perusahaan manufaktur keluarga yang cukup terkenal dan beberapa kali mendapatkan penghargaan dari Jerman, namun banyak yang perlu dibenahi dari perusahaan ini dari segi risiko yang terjadi di setiap divisi dan departemennya.

Penulis melakukan penelitian di PT XYZ pada divisi papermill yang mengidentifikasi beberapa departemen didalamnya. 
Perusahaan melaksanakan manajemen risiko untuk mengarahkan dan mengendalikan aktivitas perusahaan terkait dengan risiko yang dihadapi, sebagai jaminan pencapaian tujuan strategis perusahaan. Salah satu aktivitas dari manajemen risiko adalah risk assessment, yang terdiri dari identifikasi risiko, analisa risiko, dan evaluasi risiko. Hasil dari risk assessment adalah risk register, yang memuat daftar kejadian risiko yang mungkin terjadi, penyebab terjadinya risiko, dampak dan probabilitas terjadinya risiko, serta cara mengatasi dan mengendalikan risiko. Risk register ini kemudian dijadikan dasar penyusunan program manajemen risiko, termasuk sebagai referensi dalam menyusun rencana audit berbasis risiko, (Pertamina Training and Consulting, 2017).

Enterprise Risk Management (ERM) membantu perusahaan mempertahankan akses ke pasar modal dan sumber daya lain yang diperlukan untuk mengimplementasikan strategi dan rencana bisnisnya. Di level mikro, ERM menjadi pedoman hidup bagi manajer dan karyawan di semua level perusahaan, (Nocco \& Stulz, 2006). Literatur internasional tentang manajemen risiko perusahaan (ERM) berpendapat bahwa organisasi dapat meningkatkan kinerja mereka dengan mengadopsi pendekatan holistik untuk manajemen risiko, pengenalan dan pengembangan sistem ERM dianggap dapat mengurangi biaya langsung dan tidak langsung, serta dapat mendukung peningkatan nilai perusahaan (Florio \& Leoni, 2017).

Ada banyak klasifikasi risiko. Beberapa dari mereka mengacu pada sumber daya perusahaan, beberapa pada segmen lingkungan tertentu. Dalam pendekatan dinamis, risiko sering dikaitkan dengan proses terpisah yang terjadi di perusahaan dan lingkungannya. Dalam artikel ini klasifikasi risiko utama membagi risiko menjadi tiga kelompok umum. Yang pertama menyangkut sumber risiko internal yang terkait dengan sumber daya perusahaan dan proses yang diambil di dalam perusahaan. Kelompok kedua mencakup risiko industri yang umum untuk semua perusahaan yang ada di sektor ini. Terakhir, kelompok ketiga terletak di lingkungan perusahaan, khususnya di segmen politik, lingkungan, sosial, teknologi, ekonomi, dan hokum, (Jonek-Kowalska, 2019).

Menurut Farrell \& Gallagher identifikasi dan penilaian risiko harus dilakukan baik di tingkat korporat maupun unit bisnis, mengatur risiko menurut kategori dan sub-kategori. Dalam kaitan ini, penelitian sebelumnya menunjukkan bahwa pemantauan risiko oleh unit bisnis adalah praktik terbaik untuk mengungkap dan melacak risiko, (Florio \& Leoni, 2017).

Manfaat ERM tingkat mikro sangat penting dalam praktiknya. Seperti sistem ERM yang dirancang dengan baik memastikan bahwa semua risiko material "dimiliki", dan pertukaran pengembalian risiko dievaluasi dengan cermat, oleh manajer operasi dan karyawan di seluruh perusahaan, (Nocco \& Stulz, 2006).

The Committee of Sponsoring Organisations of the Treadway Commission (COSO) berpendapat bahwa bisnis akan terus menghadapi masa depan yang penuh ketidakpastian, (COSO, 2017). Oleh karena itu manajemen perusahan perlu melakukan mitigasi risiko disetiap divisi untuk mampu mengelola risiko di perusahaan.

Manajemen memegang tanggung jawab keseluruhan untuk mengelola risiko pada entitas, tetapi penting bagi manajemen untuk melangkah lebih jauh: untuk meningkatkan percakapan dengan pemangku kepentingan tentang penggunaan manajemen risiko perusahaan untuk mendapatkan keunggulan kompetitif. Hal tersebut dapat dimulai dengan menerapkan kemampuan manajemen risiko perusahaan sebagai bagian dari pemilihan dan penyempurnaan strategi, (COSO, 2017).

Saat ini, penggunaan metode penilaian risiko berkembang di industri yang berbeda, sehingga saat ini terdapat berbagai jenis metode penilaian risiko kualitatif dan kuantitatif dalam penelitian. Metode-metode ini biasanya digunakan untuk mengidentifikasi, mengendalikan, dan mengurangi konsekuensi dari efek risiko, (Yousefi et al., 2018). 
FMEA merupakan sebuah metode yang digunakan untuk memeriksa penyebab cacat atau kegagalan yang terjadi saat proses produksi, mengevaluasi prioritas risiko yang menyebabkan timbulnya kecelakaan kerja, dan membantu mengambil tindakan untuk menghindari masalah yang teridentifikasi sebagai bahaya kecelakaan kerja. Metode FMEA menggabungkan pengetahuan dan pengalaman manusia untuk, (J. et al., 2017): (1) mengidentifikasi potensi kegagalan dari suatu produk atau proses, (2) mengevalusi kegagalan suatu produk atau proses dan dampaknya, (3) membantu perekayasa untuk melakukan tindakan perbaikan atau tindakan preventif, dan (4) menghilangkan atau mengurangi kemungkinan terjadinya kegagalan. Metode FMEA sangat membantu dan mudah digunakan untuk mengidentifikasi dan mengukur tingkat risiko kecelakaan kerja.

Pada penelitian ini melakukan identifikasi risiko pada departmen $\mathrm{K} 3$ dan Lingkungan, PPIC, Quality Control, Produksi, Procurement dan Pergudangan, Teknik yang berkaitan dengan kegiatan produksi pada Divisi Papermill di PT XYZ.

Artikel ini bertujuan menganalisis dampak risiko perusahaan pada divisi papermill di setiap departmen di PT XYZ yang mempunyai riwayat risiko perusahaan kemudian menilai tingkat risiko tersebut, harapannya dapat menjadi masukan dan solusi perusahaan untuk mengatasi risiko yang terjadi.

\section{Metodologi}

Pada artikel ini mengidentifikasi faktorfaktor risiko pada divisi papermill di setiap departmennya, dimana analisa ini bersifat kuantitatif dengan menggunakan metode Failure Mode and Effect Analysis (FMEA). Dengan mengindentifikasi risiko perusahaan pada divisi papermill dapat dilihat seberapa besar dampak (Severity), kemungkinan terjadinya resiko (Occurace), deteksi resiko (Detection) dan hasilnya berupa Riks Priority Number (RPN) dan risiko apa saja yang terjadi pada setiap departemen. Pengambilan data dilakukan dengan pengamatan langsung dan wawancara.
Penelitian ini bertujuan menganalisis dampak risiko perusahaan pada divisi papermill di setiap departmen di PT XYZ yang mempunyai riwayat risiko perusahaan kemudian menilai tingkat risiko tersebut. Penilaian tingkat risiko dilakukan dengan metode FMEA yang menghitung nilai RPN dari tiap risiko kecelakaan kerja. Nilai RPN merupakan perkalian dari nilai $\mathrm{S}, \mathrm{O}, \mathrm{D}$ sehingga dapat diketahui risiko yg keritis dari setiap kegiatan pada divisi tersebut.

\section{Hasil dan Pembahasan}

Bab ini menjelaskan tentang hasil dari penelitian yang diperoleh. Perusahaan melaksanakan manajemen risiko untuk mengarahkan dan mengendalikan aktivitas perusahaan terkait dengan risiko yang dihadapi, sebagai jaminan pencapaian tujuan strategis perusahaan. Salah satu aktivitas dari manajemen risiko adalah risk assessment, yang terdiri dari identifikasi risiko, analisa risiko, dan evaluasi risiko, (Pertamina Training and Consulting, 2017).

\subsection{Event Risiko}

Identifikasi risiko harus dilakukan baik di tingkat korporat maupun unit bisnis, mengatur risiko menurut kategori dan sub-kategori. Dalam kaitan ini, menunjukkan bahwa pemantauan risiko oleh unit bisnis adalah praktik terbaik untuk mengungkap dan melacak risiko, (Florio \& Leoni, 2017). Event risiko pada Tabel 1. merupakan penjelasan risiko yang terjadi Divisi Papermill untuk setiap department di PT XYZ yang didapatkan dari hasil observasi lapangan dan wawancara.

Tabel 1. Event Risiko Divisi Papermill PT XYZ

\begin{tabular}{|c|c|c|c|}
\hline \multirow[b]{2}{*}{ No } & \multicolumn{3}{|c|}{ Event Risiko } \\
\hline & $\begin{array}{c}\text { Departme } \\
\mathrm{nt}\end{array}$ & $\begin{array}{l}\text { Perny } \\
\text { ataan }\end{array}$ & Variabel \\
\hline \multirow[t]{2}{*}{1} & \multirow{2}{*}{$\begin{array}{c}\mathrm{K} 3 \text { dan } \\
\text { Lingkunga } \\
\mathrm{n}\end{array}$} & 1 & $\begin{array}{l}\text { Karyawan tidak } \\
\text { menggunakan } \\
\text { pakaian kerja } \\
\text { yang aman }\end{array}$ \\
\hline & & 2 & $\begin{array}{l}\text { Kesadaran } \\
\text { penggunaan apd }\end{array}$ \\
\hline
\end{tabular}




\begin{tabular}{|c|c|c|c|}
\hline & & & rendah \\
\hline & & 3 & $\begin{array}{l}\text { Kecelakaan di } \\
\text { dapur } \\
\text { pengolahan } \\
\text { limbah }\end{array}$ \\
\hline & & 4 & $\begin{array}{l}\text { Karyawan tidak } \\
\text { disiplin di jam } \\
\text { kerja }\end{array}$ \\
\hline & & 5 & $\begin{array}{l}\text { Layout } 5 \mathrm{~s} \text { tidak } \\
\text { di perhatikan/ } \\
\text { pelanggaran } \\
\text { area-area } 5 \mathrm{~s}\end{array}$ \\
\hline & & 6 & $\begin{array}{l}\text { Kecelakaan } \\
\text { dalam } \\
\text { penggunaan } \\
\text { forklift }\end{array}$ \\
\hline \multirow{3}{*}{2} & \multirow{3}{*}{ PPIC } & 7 & $\begin{array}{l}\text { Sulit } \\
\text { menemukan } \\
\text { data }\end{array}$ \\
\hline & & 8 & $\begin{array}{l}\text { Tracking barang } \\
\text { lama (manual) }\end{array}$ \\
\hline & & 9 & $\begin{array}{l}\text { Kesalahan } \\
\text { dalam prediksi } \\
\text { dan informasi } \\
\text { barang tersedia }\end{array}$ \\
\hline \multirow{5}{*}{3} & \multirow{5}{*}{$\begin{array}{l}\text { Quality } \\
\text { Control }\end{array}$} & 10 & $\begin{array}{l}\text { Beberapa alat } \\
\text { test tidak } \\
\text { berfungsi } \\
\text { dengan baik }\end{array}$ \\
\hline & & 11 & $\begin{array}{l}\text { Kedisiplinan } \\
\text { waktu test }\end{array}$ \\
\hline & & 12 & $\begin{array}{l}\text { Administrasi } \\
\text { dan pencatatan } \\
\text { hasil test manual }\end{array}$ \\
\hline & & 13 & $\begin{array}{l}\text { Sampel tidak di } \\
\text { cek di semua } \\
\text { alat test yang } \\
\text { ditentuakan } \\
\text { dalam sop }\end{array}$ \\
\hline & & 14 & $\begin{array}{l}\text { Kurangnya } \\
\text { maintenance alat } \\
\text { test }\end{array}$ \\
\hline \multirow{2}{*}{4} & \multirow{2}{*}{ Produksi } & 15 & $\begin{array}{l}\text { Kecelakaan } \\
\text { kerja saat mesin } \\
\text { error }\end{array}$ \\
\hline & & 16 & $\begin{array}{ll}\text { Organ } & \text { tubuh } \\
\text { operator } & \text { cidera/ } \\
\text { patah } & \end{array}$ \\
\hline
\end{tabular}

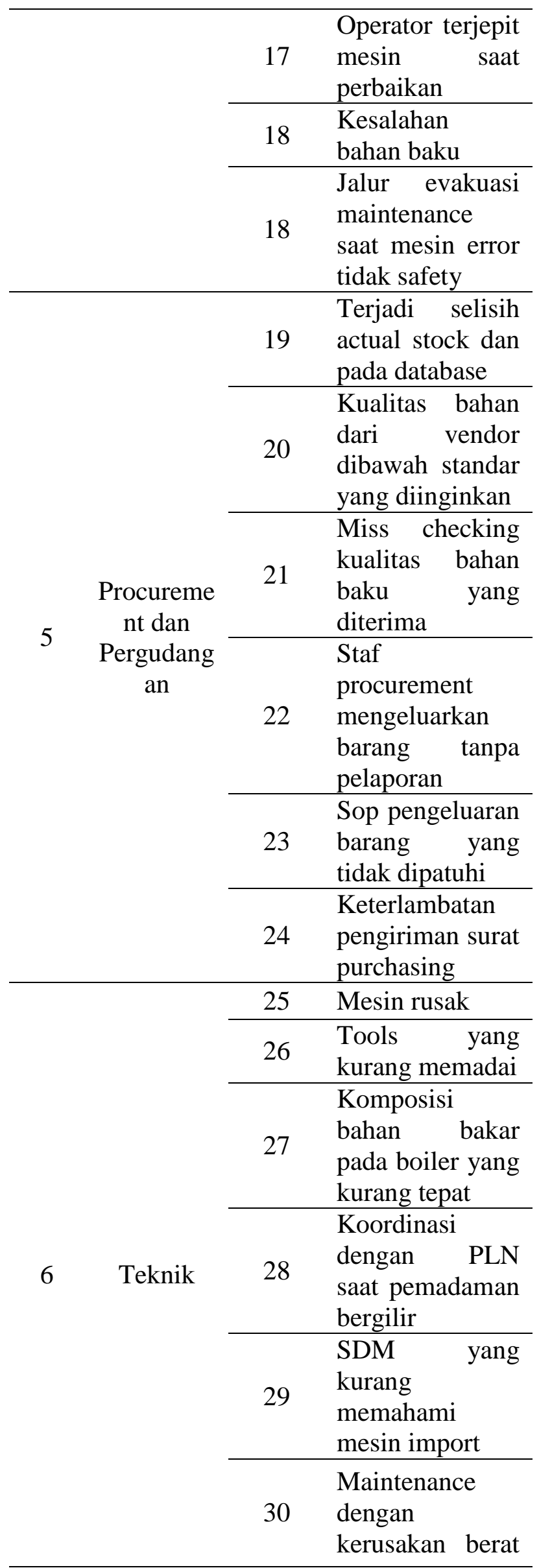




\begin{tabular}{ll}
\hline harus \\
mendatangkan \\
ahli dari Jerman/ \\
China \\
\hline
\end{tabular}

\subsection{Event Risiko}

Setelah daftar potensi kegagalan dibentuk, langkah berikutnya adalah mengumpulkan data frekuensi kejadian dari masing-masing daftar potensi kegagalan berdasarkan hasil pengamatan langsung, (Budiarto, 2017). Atau membuat Risk breakdown structure dan perhitungan RPN seperti tabel 2, dimana ada faktor yang menentukan risiko perlu penanganan segera, yaitu severity, occurance dan detection, (Mansur \& Ratnasari, 2015).

Tabel 2. Event Risiko Divisi Papermill PT $\mathrm{XYZ}$

\begin{tabular}{|c|c|c|c|c|c|c|}
\hline No & $\begin{array}{l}\text { Dep } \\
\text { arte } \\
\text { ment }\end{array}$ & $\begin{array}{l}\text { Perny } \\
\text { ataan }\end{array}$ & $S$ & $\mathrm{O}$ & $\mathrm{D}$ & RPN \\
\hline \multirow{6}{*}{1} & \multirow{6}{*}{$\begin{array}{c}\text { K3 } \\
\text { dan } \\
\text { Ling } \\
\text { kung } \\
\text { an }\end{array}$} & 1 & 6 & 2 & 1 & 12 \\
\hline & & 2 & 6 & 2 & 1 & 12 \\
\hline & & 3 & $\begin{array}{l}1 \\
0\end{array}$ & 2 & 3 & 60 \\
\hline & & 4 & 6 & 2 & 2 & 24 \\
\hline & & 5 & 7 & 3 & 5 & 105 \\
\hline & & 6 & 7 & 3 & 4 & 84 \\
\hline \multirow{3}{*}{2} & \multirow{3}{*}{$\begin{array}{c}\text { PPI } \\
\mathrm{C}\end{array}$} & 7 & 2 & 2 & 3 & 12 \\
\hline & & 8 & 2 & 2 & 3 & 12 \\
\hline & & 9 & 5 & 2 & 4 & 40 \\
\hline \multirow{4}{*}{3} & \multirow{4}{*}{$\begin{array}{l}\text { Qual } \\
\text { ity } \\
\text { Cont } \\
\text { rol }\end{array}$} & 10 & 6 & 2 & 6 & 72 \\
\hline & & 11 & 4 & 2 & 3 & 24 \\
\hline & & 12 & 2 & 2 & 3 & 12 \\
\hline & & 13 & 4 & 2 & 3 & 24 \\
\hline
\end{tabular}

\begin{tabular}{|c|c|c|c|c|c|c|}
\hline & & 14 & 4 & 3 & 4 & 48 \\
\hline \multirow{5}{*}{4} & \multirow{5}{*}{$\begin{array}{l}\text { Prod } \\
\text { uksi }\end{array}$} & 15 & 6 & 1 & 8 & 48 \\
\hline & & 16 & $\begin{array}{l}1 \\
0\end{array}$ & 1 & 8 & 80 \\
\hline & & 17 & $\begin{array}{l}1 \\
0\end{array}$ & 1 & 8 & 80 \\
\hline & & 18 & 7 & 2 & 4 & 56 \\
\hline & & 19 & $\begin{array}{l}1 \\
\mathbf{0}\end{array}$ & 3 & 5 & 150 \\
\hline \multirow{6}{*}{5} & \multirow{6}{*}{$\begin{array}{c}\text { Proc } \\
\text { urem } \\
\text { ent } \\
\text { dan } \\
\text { Perg } \\
\text { udan } \\
\text { gan }\end{array}$} & 20 & 6 & 4 & 3 & 72 \\
\hline & & 21 & 6 & 3 & 3 & 54 \\
\hline & & 22 & 5 & 3 & 3 & 45 \\
\hline & & 23 & 6 & 3 & 3 & 54 \\
\hline & & 24 & 4 & 3 & 3 & 36 \\
\hline & & 25 & 2 & 2 & 3 & 12 \\
\hline \multirow{5}{*}{6} & \multirow{5}{*}{$\begin{array}{c}\text { Tekn } \\
\text { ik }\end{array}$} & 26 & 6 & 3 & 5 & 90 \\
\hline & & 27 & 5 & 4 & 4 & 80 \\
\hline & & 28 & 8 & 3 & 4 & 96 \\
\hline & & 29 & 7 & 2 & 4 & 56 \\
\hline & & 30 & 6 & 2 & 4 & 48 \\
\hline
\end{tabular}

\section{$\begin{array}{lllll}31 & 8 & 2 & 4 & 64\end{array}$}

\begin{tabular}{ccccc}
\hline & 1 & 7 & 12 & 1662 \\
Total & 8 & 3 & 1 & \\
& 3 & & & \\
& & 2, & & \\
Average & 5, & 3 & & \\
& 9 & 5 & 3,9 & $\mathbf{5 3 , 6 1}$ \\
& 0 & 4 & 03 & $\mathbf{2 9}$ \\
& 3 & 8 & 23 & \\
& 2 & 3 & & \\
Nilai Krisis RPN & $\mathbf{5 3 , 6 1}$ & \\
Risiko & $\mathbf{2 9}$ & \\
\cline { 1 - 2 } & &
\end{tabular}




\subsection{Risk Register}

Selanjutnya dibuat tabel Risk Register, yaitu yang memuat daftar kejadian risiko yang mungkin terjadi, penyebab terjadinya risiko, dampak dan probabilitas terjadinya risiko, serta cara mengatasi dan mengendalikan risiko. Risk register ini kemudian dijadikan dasar penyusunan program manajemen risiko, termasuk sebagai referensi dalam menyusun rencana audit berbasis risiko, (Pertamina Training and Consulting, 2017). Tabel 3. merupakan tabel Risk Registernya:

Tabel 3. Risk Register

\begin{tabular}{|c|c|c|c|c|c|}
\hline \multirow[b]{2}{*}{ No } & \multirow[b]{2}{*}{ Sasaran } & \multirow{2}{*}{$\begin{array}{l}\text { Kategori } \\
\text { Risiko }\end{array}$} & \multicolumn{2}{|c|}{ Risiko } & \multirow{2}{*}{$\begin{array}{c}\text { Deskripsi } \\
\text { Konsekuansi } \\
\text { Risiko } \\
\end{array}$} \\
\hline & & & Apa yang Mungkin Terjadi & $\begin{array}{l}\text { Penyebab } \\
\text { Terjadinya }\end{array}$ & \\
\hline 1 & \multirow{6}{*}{$\begin{array}{c}\text { K3 dan } \\
\text { Lingkungan }\end{array}$} & Medium & $\begin{array}{lr}\text { Karyawan } & \text { tidak } \\
\text { menggunakan } & \text { pakaian } \\
\text { kerja yang aman } & \end{array}$ & $\begin{array}{l}\text { Kurangnya } \\
\text { pengawasan dan } \\
\text { reward-punishment }\end{array}$ & $\begin{array}{l}\text { Terjadi } \\
\text { kecelakaan kerja } \\
\text { rendah-tinggi }\end{array}$ \\
\hline 2 & & Medium & $\begin{array}{l}\text { Kesadaran penggunaan } \\
\text { APD rendah }\end{array}$ & $\begin{array}{l}\text { Kurangnya } \\
\text { pengawasan dan } \\
\text { reward-punishment }\end{array}$ & $\begin{array}{l}\text { Terjadi } \\
\text { kecelakaan kerja } \\
\text { rendah-tinggi }\end{array}$ \\
\hline 3 & & Medium & $\begin{array}{l}\text { Kecelakaan di dapur } \\
\text { pengolahan limbah }\end{array}$ & $\begin{array}{l}\text { Tidak hati-hati dan } \\
\text { kurang } \\
\text { memperhatikan } \\
\text { rambu }\end{array}$ & $\begin{array}{l}\text { Terjadi } \\
\text { kecelakaan kerja } \\
\text { dan sampel } \\
\text { limbah tercemar }\end{array}$ \\
\hline 4 & & Low & $\begin{array}{l}\text { Karyawan tidak disiplin di } \\
\text { jam kerja }\end{array}$ & $\begin{array}{l}\text { Kurangnya } \\
\text { pengawasan dan } \\
\text { reward-punishment }\end{array}$ & $\begin{array}{l}\text { Produktivitas } \\
\text { menurun }\end{array}$ \\
\hline 5 & & High & $\begin{array}{lcr}\text { layout } 5 \mathrm{~S} & \text { tidak di } \\
\text { perhatikan/ } & \text { Pelanggaran } \\
\text { area-area 5S } & \end{array}$ & $\begin{array}{l}\text { Kurangnya } \\
\text { pengawasan dan } \\
\text { reward-punishment }\end{array}$ & $\begin{array}{l}\text { Terjadi } \\
\text { kecelakaan kerja } \\
\text { rendah-tinggi }\end{array}$ \\
\hline 6 & & High & $\begin{array}{l}\text { kecelakaan dalam } \\
\text { penggunaan forklift }\end{array}$ & $\begin{array}{l}\text { Layout dan } 5 \mathrm{~S} \text { tidak } \\
\text { dipatuhi }\end{array}$ & $\begin{array}{l}\text { Terjadi } \\
\text { kecelakaan kerja } \\
\text { rendah-tinggi }\end{array}$ \\
\hline 7 & \multirow{3}{*}{ PPIC } & Low & Sulit menemukan data & $\begin{array}{l}\text { Administrasi } \\
\text { manual }\end{array}$ & $\begin{array}{l}\text { Efisiensi } \\
\text { menurun/ } \\
\text { wasting time } \\
\end{array}$ \\
\hline 8 & & Low & $\begin{array}{l}\text { Tracking barang lama } \\
\text { (manual) }\end{array}$ & $\begin{array}{l}\text { Teknologi informasi } \\
\text { tidak digunakan } \\
\text { dengan maksimal }\end{array}$ & $\begin{array}{l}\text { Efisiensi } \\
\text { menurun/ } \\
\text { wasting time }\end{array}$ \\
\hline 9 & & Low & $\begin{array}{l}\text { kesalahan dalam prediksi } \\
\text { dan informasi barang } \\
\text { tersedia }\end{array}$ & $\begin{array}{l}\text { Administrasi } \\
\text { manual }\end{array}$ & $\begin{array}{l}\text { Efisiensi } \\
\text { menurun/ } \\
\text { wasting time } \\
\text { dan perlu } \\
\text { pengecekan } \\
\text { ulang }\end{array}$ \\
\hline 10 & $\begin{array}{l}\text { Quality } \\
\text { Control }\end{array}$ & Medium & $\begin{array}{l}\text { beberapa alat test tidak } \\
\text { berfungsi dengan baik }\end{array}$ & $\begin{array}{l}\text { Kurangnya } \\
\text { pengecekan rutin }\end{array}$ & $\begin{array}{l}\text { Hasil cek } \\
\text { kualitas menjadi } \\
\text { kurang akurat }\end{array}$ \\
\hline
\end{tabular}




\begin{tabular}{|c|c|c|c|c|c|}
\hline 11 & & Medium & kedisiplinan waktu test & $\begin{array}{l}\text { Kurangnya } \\
\text { pengawasan dan } \\
\text { reward-punishment }\end{array}$ & $\begin{array}{l}\text { Hasil cek } \\
\text { kualitas menjadi } \\
\text { kurang akurat }\end{array}$ \\
\hline 12 & & Low & $\begin{array}{l}\text { administrasi dan pencatatan } \\
\text { hasil test manual }\end{array}$ & $\begin{array}{l}\text { Teknologi informasi } \\
\text { tidak digunakan } \\
\text { dengan maksimal }\end{array}$ & $\begin{array}{l}\text { informasi data } \\
\text { menjadi lama }\end{array}$ \\
\hline 13 & & Medium & $\begin{array}{l}\text { sampel tidak di cek di } \\
\text { semua alat test yang } \\
\text { ditentuakan dalam SOP }\end{array}$ & $\begin{array}{l}\text { Kurangnya } \\
\text { pengawasan dan } \\
\text { reward-punishment }\end{array}$ & $\begin{array}{l}\text { standar kualitas } \\
\text { tidak terpenuhi }\end{array}$ \\
\hline 14 & & Medium & $\begin{array}{l}\text { kurangnya maintenance } \\
\text { alat test }\end{array}$ & $\begin{array}{l}\text { Kurangnya } \\
\text { pengawasan dan } \\
\text { reward-punishment }\end{array}$ & $\begin{array}{l}\text { beberapa alat } \\
\text { test tidak } \\
\text { berfungsi } \\
\text { dengan baik }\end{array}$ \\
\hline 15 & \multirow{5}{*}{ Produksi } & High & $\begin{array}{l}\text { Kecelakaan kerja saat } \\
\text { mesin error }\end{array}$ & $\begin{array}{l}\text { Tidak hati-hati dan } \\
\text { kurang } \\
\text { memperhatikan } \\
\text { rambu }\end{array}$ & $\begin{array}{l}\text { Cidera ringan- } \\
\text { berat }\end{array}$ \\
\hline 16 & & High & $\begin{array}{l}\text { organ tubuh operator } \\
\text { cidera/ patah }\end{array}$ & $\begin{array}{l}\text { Tidak hati-hati dan } \\
\text { kurang } \\
\text { memperhatikan } \\
\text { rambu }\end{array}$ & Cacat \\
\hline 17 & & High & $\begin{array}{l}\text { operator terjepit mesin saat } \\
\text { perbaikan }\end{array}$ & $\begin{array}{l}\text { Tidak hati-hati dan } \\
\text { kurang } \\
\text { memperhatikan } \\
\text { rambu }\end{array}$ & $\begin{array}{l}\text { Cidera ringan- } \\
\text { berat }\end{array}$ \\
\hline 18 & & High & kesalahan bahan baku & $\begin{array}{l}\text { Lalai dan kurang } \\
\text { pengawasan }\end{array}$ & $\begin{array}{l}\text { Kualitas tidak } \\
\text { sesuai standar }\end{array}$ \\
\hline 18 & & High & $\begin{array}{l}\text { Jalur evakuasi maintenance } \\
\text { saat mesin error tidak } \\
\text { safety }\end{array}$ & $\begin{array}{l}\text { Layout dan } 5 \mathrm{~S} \text { yang } \\
\text { tidak memenuhi } \\
\text { standar keamanan }\end{array}$ & $\begin{array}{l}\text { Kecelakaan } \\
\text { kerja ringan- } \\
\text { berat }\end{array}$ \\
\hline 19 & \multirow{4}{*}{$\begin{array}{l}\text { Procurement } \\
\text { dan } \\
\text { Pergudangan }\end{array}$} & Low & $\begin{array}{l}\text { Terjadi selisih actual stock } \\
\text { dan pada database }\end{array}$ & $\begin{array}{l}\text { Teknologi informasi } \\
\text { tidak digunakan } \\
\text { dengan maksimal }\end{array}$ & $\begin{array}{l}\text { Biaya inventory } \\
\text { tinggi atau stock } \\
\text { out }\end{array}$ \\
\hline 20 & & Low & $\begin{array}{l}\text { Kualitas bahan dari vendor } \\
\text { dibawah standar yang } \\
\text { diinginkan }\end{array}$ & $\begin{array}{l}\text { Kurangnya } \\
\text { pengecekan } r \text { saat } \\
\text { penerimaan bahan } \\
\text { baku }\end{array}$ & $\begin{array}{l}\text { Kualitas tidak } \\
\text { sesuai standar }\end{array}$ \\
\hline 21 & & Low & $\begin{array}{l}\text { Miss checking kualitas } \\
\text { bahan baku yang diterima }\end{array}$ & $\begin{array}{l}\text { Kurangnya } \\
\text { pengecekan } \\
\text { penerimaan } \\
\text { baku }\end{array}$ & $\begin{array}{l}\text { Kualitas tidak } \\
\text { sesuai standar }\end{array}$ \\
\hline 22 & & Medium & $\begin{array}{l}\text { Staf procurement } \\
\text { mengeluarkan barang tanpa } \\
\text { pelaporan }\end{array}$ & $\begin{array}{l}\text { Kurangnya } \\
\text { pengawasan dan } \\
\text { reward-punishment }\end{array}$ & $\begin{array}{l}\text { Terjadi selisih } \\
\text { actual stock dan } \\
\text { pada database }\end{array}$ \\
\hline
\end{tabular}




\begin{tabular}{|c|c|c|c|c|c|}
\hline 23 & & Medium & $\begin{array}{l}\text { SOP pengeluaran barang } \\
\text { yang tidak dipatuhi }\end{array}$ & $\begin{array}{l}\text { Kurangnya } \\
\text { pengawasan dan } \\
\text { reward-punishment }\end{array}$ & $\begin{array}{l}\text { Terjadi selisih } \\
\text { actual stock dan } \\
\text { pada database }\end{array}$ \\
\hline 24 & & Medium & $\begin{array}{l}\text { Keterlambatan pengiriman } \\
\text { surat purchasing }\end{array}$ & $\begin{array}{l}\text { Kurangnya } \\
\text { pengawasan dan } \\
\text { reward-punishment }\end{array}$ & $\begin{array}{l}\text { Miss informasi } \\
\text { ketersediaan } \\
\text { barang di } \\
\text { gudang } \\
\text { stock out } \\
\end{array}$ \\
\hline 25 & & High & Mesin rusak & $\begin{array}{l}\text { Jadwal maintenance } \\
\text { yang kurang baik }\end{array}$ & $\begin{array}{l}\text { Produksi } \\
\text { berhenti }\end{array}$ \\
\hline 26 & & Medium & $\begin{array}{l}\text { Tools yang kurang } \\
\text { memadai }\end{array}$ & Efiesiensi biaya & $\begin{array}{l}\text { Efisiensi tidak } \\
\text { maksimal }\end{array}$ \\
\hline 27 & & High & $\begin{array}{l}\text { komposisi bahan } \text { bakar } \\
\text { pada boiler yang kurang } \\
\text { tepat }\end{array}$ & $\begin{array}{l}\text { Kualitas batu bara } \\
\text { yang tidak stabil }\end{array}$ & $\begin{array}{l}\text { Operasional } \\
\text { produksi } \\
\text { terganggu }\end{array}$ \\
\hline 28 & Teknik & Medium & $\begin{array}{l}\text { Koordinasi dengan PLN } \\
\text { saat pemadaman bergilir }\end{array}$ & \begin{tabular}{llr} 
Miss & \multicolumn{2}{c}{ komunikasi } \\
dalam & \multicolumn{2}{c}{ penggunaan } \\
listrik & PLN & dan \\
Power & Plan & Pura \\
Group & & \\
\end{tabular} & $\begin{array}{l}\text { tidak } \\
\text { menyiapkan } \\
\text { daya cadangan } \\
\text { atau antisipasi }\end{array}$ \\
\hline 29 & & Medium & $\begin{array}{l}\text { SDM yang kurang } \\
\text { memahami mesin import }\end{array}$ & $\begin{array}{l}\text { SDM kurang } \\
\text { berpengalaman }\end{array}$ & $\begin{array}{l}\text { Kerusakan } \\
\text { mesin tidak } \\
\text { dapat diperbaiki } \\
\text { sendiri }\end{array}$ \\
\hline 30 & & High & $\begin{array}{l}\text { Maintenance } \\
\text { kerusakan berat harus } \\
\text { mendatangkan ahli dari } \\
\text { Jerman/ China }\end{array}$ & $\begin{array}{lr}\text { Tidak ada tenaga } \\
\text { ahli di } & \text { perusahaan } \\
\text { yang } & \text { menguasai } \\
\text { mesin } & \\
\end{array}$ & $\begin{array}{l}\text { Anggaran biaya } \\
\text { yang besar }\end{array}$ \\
\hline
\end{tabular}

\subsection{Klasifikasi Risiko}

Klasifikasi Risiko merupakan pengelompokan risiko berdasarkan impak dan sering atau tidaknya risiko terjadi. Dalam pendekatan dinamis, risiko sering dikaitkan dengan proses terpisah yang terjadi di perusahaan dan lingkungannya. Kalsifikasi Risiko dibagi menjadi 3, namun dalam artikel ini menyangkut sumber risiko internal yang terkait dengan sumber daya perusahaan dan proses yang diambil di dalam perusahaan, yang merupakan risiko yang pertama, (JonekKowalska, 2019). Tabel 4 merupakan Klasifikasi risiko di PT XYZ.
Tabel 4. Klasifikasi Risiko

\begin{tabular}{|c|c|c|}
\hline No & $\begin{array}{l}\text { Klasifikasi } \\
\text { Risiko }\end{array}$ & Risiko \\
\hline 5 & \multirow{7}{*}{ High } & $\begin{array}{lcr}\text { layout } \quad 5 \mathrm{~S} & \text { tidak di } \\
\text { perhatikan/ } & \text { Pelanggaran } \\
\text { area-area 5S } & \end{array}$ \\
\hline 6 & & $\begin{array}{l}\text { kecelakaan dalam } \\
\text { penggunaan forklift }\end{array}$ \\
\hline 15 & & $\begin{array}{l}\text { Kecelakaan kerja saat } \\
\text { mesin error }\end{array}$ \\
\hline 16 & & $\begin{array}{l}\text { organ tubuh operator } \\
\text { cidera/ patah }\end{array}$ \\
\hline 17 & & $\begin{array}{l}\text { operator terjepit mesin saat } \\
\text { perbaikan }\end{array}$ \\
\hline 18 & & kesalahan bahan baku \\
\hline 18 & & \begin{tabular}{llr} 
Jalur & \multicolumn{2}{c}{ evakuasi } \\
maintenance & saat $\quad$ mesin \\
\end{tabular} \\
\hline
\end{tabular}




\begin{tabular}{|c|c|c|}
\hline & & error tidak safety \\
\hline 25 & & Mesin rusak \\
\hline 27 & & $\begin{array}{l}\text { komposisi bahan bakar } \\
\text { pada boiler yang kurang } \\
\text { tepat }\end{array}$ \\
\hline 30 & & $\begin{array}{l}\text { Maintenance } \\
\text { kerusakan berat harus } \\
\text { mendatangkan ahli dari } \\
\text { Jerman/ China }\end{array}$ \\
\hline 1 & \multirow{13}{*}{ Medium } & $\begin{array}{lr}\text { Karyawan } & \text { tidak } \\
\text { menggunakan } & \text { pakaian } \\
\text { kerja yang aman } & \end{array}$ \\
\hline 2 & & $\begin{array}{ll}\text { Kesadaran penggunaan } \\
\text { APD rendah }\end{array}$ \\
\hline 3 & & $\begin{array}{l}\text { Kecelakaan di dapur } \\
\text { pengolahan limbah }\end{array}$ \\
\hline 10 & & $\begin{array}{l}\text { beberapa alat test tidak } \\
\text { berfungsi dengan baik }\end{array}$ \\
\hline 11 & & kedisiplinan waktu test \\
\hline 13 & & $\begin{array}{l}\text { sampel tidak di cek di } \\
\text { semua alat test yang } \\
\text { ditentuakan dalam SOP }\end{array}$ \\
\hline 14 & & $\begin{array}{l}\text { kurangnya maintenance } \\
\text { alat test }\end{array}$ \\
\hline 22 & & $\begin{array}{l}\text { Staf procurement } \\
\text { mengeluarkan } \quad \text { barang } \\
\text { tanpa pelaporan }\end{array}$ \\
\hline 23 & & $\begin{array}{l}\text { SOP pengeluaran barang } \\
\text { yang tidak dipatuhi }\end{array}$ \\
\hline 24 & & $\begin{array}{l}\text { Keterlambatan pengiriman } \\
\text { surat purchasing }\end{array}$ \\
\hline 26 & & $\begin{array}{l}\text { Tools yang kurang } \\
\text { memadai }\end{array}$ \\
\hline 28 & & $\begin{array}{l}\text { Koordinasi dengan PLN } \\
\text { saat pemadaman bergilir }\end{array}$ \\
\hline 29 & & $\begin{array}{l}\text { SDM yang kurang } \\
\text { memahami mesin import }\end{array}$ \\
\hline 4 & \multirow{6}{*}{ Low } & $\begin{array}{l}\text { Karyawan tidak disiplin di } \\
\text { jam kerja }\end{array}$ \\
\hline 7 & & Sulit menemukan data \\
\hline 8 & & $\begin{array}{l}\text { Tracking barang lama } \\
\text { (manual) }\end{array}$ \\
\hline 9 & & $\begin{array}{l}\text { kesalahan dalam prediksi } \\
\text { dan informasi barang } \\
\text { tersedia }\end{array}$ \\
\hline 12 & & 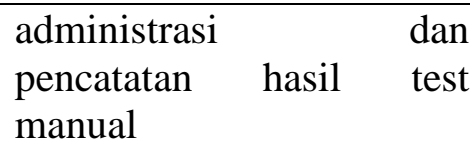 \\
\hline 19 & & Terjadi selisih actual stock \\
\hline
\end{tabular}

\begin{tabular}{ll}
\hline & \multicolumn{2}{c}{ dan pada database } \\
\cline { 3 - 3 } 20 & $\begin{array}{l}\text { Kualitas bahan dari vendor } \\
\text { dibawah standar yang } \\
\text { diinginkan }\end{array}$ \\
& $\begin{array}{l}\text { Miss checking kualitas } \\
\text { bahan baku yang diterima }\end{array}$ \\
\hline
\end{tabular}

\subsection{Risk Prioritization Matrix}

Setelah risiko di klasifikasikan maka dapat digambarkan letak dari matrik prioritasnya, dengan grafik untuk mempermudah top manajemen menganalisa risiko mana yang paling penting untuk diminimalisir. Gambar 1 merupakan Risk Prioritization Matrix.

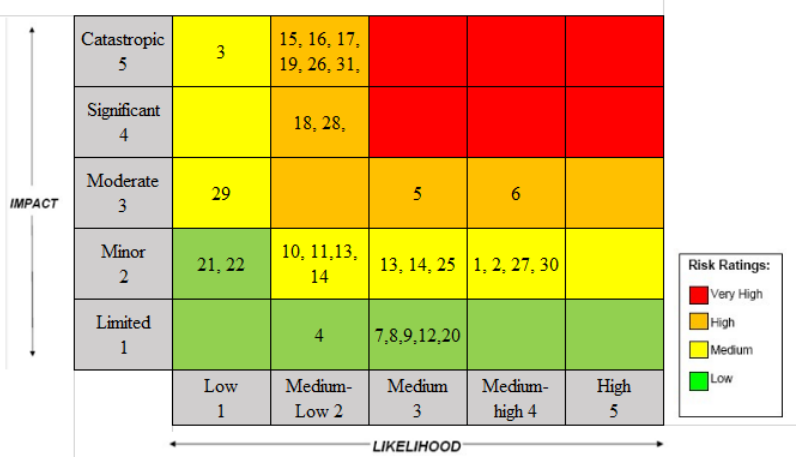

Gambar 1. Risk Prioritization Matrix 


\section{Kesimpulan}

Bagian ini terdiri dari kesimpulan dan juga saran. Kesimpulan harus merupakan jawaban dari masalah penelitian, dan berupa pernyataan tegas. Saran haruslah logis dan sesuai.

Dilihat dari risiko yang perlu segera di atasi melihat nilai RPN nya, kemudian di breakdown dalam risk prioritazion matrix, maka ada 10 risiko tinggi yang perlu diatangani dengan segera, yaitu: layout $5 \mathrm{~S}$ tidak di perhatikan/ Pelanggaran area-area 5S, kecelakaan dalam penggunaan forklift, Kecelakaan kerja saat mesin error, organ tubuh operator cidera/ patah, operator terjepit mesin saat perbaikan, kesalahan bahan baku, Jalur evakuasi maintenance saat mesin error tidak safety, Mesin rusak, komposisi bahan bakar pada boiler yang kurang tepat, Maintenance dengan kerusakan berat harus mendatangkan ahli dari Jerman/ China.

Sedangkan untuk risiko mediumnya ada 13 risiko, yaitu : Karyawan tidak menggunakan pakaian kerja yang aman, Kesadaran penggunaan APD rendah, Kecelakaan di dapur pengolahan limbah, beberapa alat test tidak berfungsi dengan baik, kedisiplinan waktu test, Staf procurement mengeluarkan barang tanpa pelaporan, SOP pengeluaran barang yang tidak dipatuhi, Keterlambatan pengiriman surat purchasing, Tools yang kurang memadai, Koordinasi dengan PLN saat pemadaman bergilir, SDM yang kurang memahami mesin import.

Sedangkan untuk risiko Lownya ada 8 risiko, yaitu : Karyawan tidak disiplin di jam kerja, Sulit menemukan data, Tracking barang lama (manual), kesalahan dalam prediksi dan informasi barang tersedia, administrasi dan pencatatan hasil test manual, Terjadi selisih actual stock dan pada database, Kualitas bahan dari vendor dibawah standar yang diinginkan, Miss checking kualitas bahan baku yang diterima.

Kemudian untuk saran yang diusulkan mengenai tindakan prefentif yang perlu dilakukan perusahaan untuk meminimalisir risiko yaitu:
1. Masalah aplikasi K3, Kedisiplinan dan penerapan SOP setiap pekerjaan perlu ditingkatkannya pengawasan di setiap divisi, sehingga akibat-akibat dari ketidakdisiplinan dapat diminimalisir, atau bahkan perlu juga diberlakukan sistem reward dan punishment.

2. Masalah kesalahan-kesalahan prediksi dan pendataan yang manual, sehingga sering terjadinya miss pelaporan perlu dilakukan perombakan dalam teknologi informasi yang digunakan. Sebenarnya Pura Group sudah memiliki aplikasi semacam SAP yang diberi nama Smart, hanya saja SDM masih merasa kesulitan bahkan malas untuk menggunakannya, maka perlu ditertibkan dan di berlakukan kewajiban. Jika perlu juga diberlakukan sistem reward dan punishment dengan penilaian KPI setiap department.

\section{Daftar Pustaka}

Budiarto, R. (2017). Penerapan Metode FMEA Untuk Keamanan sistem Informasi. Seminar Nasional IPTEK Terapan(SENIT)2017, 1, 73-78. https://doi.org/10.1021/ie201692q

Callahan, C., \& Soileau, J. (2017). Does Enterprise risk management enhance operating performance? Advances in Accounting, 37, 122-139. https://doi.org/10.1016/j.adiac.2017.01.0 01

Cantonnet, M. L., Aldasoro, J. C., \& Iradi, J. (2019). New and emerging risks management in small and medium-sized Spanish enterprises. Safety Science, 113(November 2018), 257-263. https://doi.org/10.1016/j.ssci.2018.11.032 COSO. (2017). Enterprise Risk Management. Integrating with strategy and performance. In The Committee of Sponsoring Organizations of the Treadway Commission (Issue June, p. 16).

https://www.coso.org/Documents/2017COSO-ERM-Integrating-with-Strategy- 
and-Performance-Executive-

Summary.pdf

Fitriyan, R. (2016). EQUIPMENT FAILURE RISK ANALYSIS USING FMEA TO IMPROVE PREDICTIVE MAINTENANCE. Institut Teknologi Sebelas November.

Florio, C., \& Leoni, G. (2017). Enterprise risk management and firm performance: The Italian case. British Accounting Review, 49(1), 56-74 https://doi.org/10.1016/j.bar.2016.08.003

Fraser, J. R. S., \& Simkins, B. J. (2016). The challenges of and solutions for implementing enterprise risk management. Business Horizons, 59(6), 689-698.

https://doi.org/10.1016/j.bushor.2016.06. 007

J., A., H., S., \& W.I., E. (2017). Analisis Risiko Kecelakaan Kerja Pada Proyek Bangunan Gedung Dengan Metode Fmea. Jurnal Muara Sains, Teknologi, Kedokteran Dan Ilmu Kesehatan, 1(1), 115-123.

https://doi.org/10.24912/jmstkik.v1i1.419

Jonek-Kowalska, I. (2019). Efficiency of Enterprise Risk Management (ERM)systems. Comparative analysis in the fuel sector and energy sector on the basis of Central-European companies listed on the Warsaw Stock Exchange. Resources Policy, 62(April), 405-415. https://doi.org/10.1016/j.resourpol.2019.0 4.011

Mansur, A., \& Ratnasari, R. (2015). Analisis Risiko Mesin Bagging Scale Dengan Metode Fuzzy Failure Mode and Affact Analysis (Fuzzy-Fmea) Di Area Pengantongan Pupuk Urea Pt. Pupuk Sriwijaja. Teknoin, 21(4). https://doi.org/10.20885/teknoin.vol21.iss 4.art2

Meidell, A., \& Kaarbøe, K. (2017). How the enterprise risk management function influences decision-making in the organization - A field study of a large, global oil and gas company. British Accounting Review, 49(1), 39-55. https://doi.org/10.1016/j.bar.2016.10.005

Nocco, B. W., \& Stulz, R. M. (2006). Enterprise Risk Management: Theory and Practice. Journal of Applied Corporate Finance, $18(4)$. https://onlinelibrary.wiley.com/doi/abs/1 0.1111/j.1745-6622.2006.00106.x

Oliva, F. L. (2016). A maturity model for enterprise risk management. International Journal of Production Economics, 173, 66-79. https://doi.org/10.1016/j.ijpe.2015.12.007

Pertamina Training and Consulting. (2017). Penyusunan Risk Register Divisi Tahun 2018 PT Pertamina Training \& Consulting. https://www.pertaminaptc.com/penyusunan-risk-register-divisitahun-2018-pt-pertamina-trainingconsulting/

Saeidi, P., Saeidi, S. P., Sofian, S., Saeidi, S. P., Nilashi, M., \& Mardani, A. (2019). The impact of enterprise risk management on competitive advantage by moderating role of information technology. Computer Standards and Interfaces, 63(November 2018), 67-82. https://doi.org/10.1016/j.csi.2018.11.009

Yousefi, S., Alizadeh, A., Hayati, J., \& Baghery, M. (2018). HSE risk prioritization using robust DEA-FMEA approach with undesirable outputs: A study of automotive parts industry in Iran. Safety Science, 102(September 2017), 144-158. https://doi.org/10.1016/j.ssci.2017.10.015 